\title{
High rate of injuries among students in Southern Nigeria: An urgent call to action
}

\author{
Jephtha C. Nmor ${ }^{1,2 \#}$, Kehi H. Nwaka ${ }^{2,3}$, Kensuke Goto ${ }^{4}$, Junko Toyosawa $^{1}$, Daisuke Fujita $^{1 \#}$ \\ ${ }^{1}$ National Mental Support Center for School Crisis, Osaka Kyoiku University, Osaka, Japan; \\ ${ }^{\#}$ Corresponding Authors: fujitad@cc.osaka-kyoiku.ac.jp, jcnmor@yahoo.com \\ ${ }^{2}$ Department of Animal and Environmental Biology, Delta State University, Abraka, Nigeria \\ ${ }^{3}$ Anthony Model School, Ubuluku, Nigeria \\ ${ }^{4}$ Department of Eco-Epidemiology, Institute of Tropical Medicine (NEKKEN), Nagasaki University, Nagasaki, Japan
}

Received 14 October 2013; revised 15 November 2013; accepted 28 November 2013

Copyright (C) 2013 Jephtha C. Nmor et al. This is an open access article distributed under the Creative Commons Attribution License, which permits unrestricted use, distribution, and reproduction in any medium, provided the original work is properly cited.

\section{ABSTRACT}

Addressing injury and its associated effects is a multi-dimensional and ongoing challenge. This includes recognizing that injury is a significant public health problem capable of affecting the health and wellbeing of all populations over short and longer terms, albeit in varied ways and intensities. That recognition has drawn attention to the need to take actions to avert its rate of occurrence particularly in developed nations. While in low-income countries, despite the growing burden of injury, there are few school-based studies from which to develop prevention initiatives. Thus this study describes the cause, nature and types and prevalence of injuries in a cross sectional population of students in Southern Nigeria, in order to provide data for use in developing priorities for injury prevention efforts. An interviewer-administered school-based survey of students attending schools in Southern Nigeria was conducted in 2013. The study sample involved 585 students (60.9\% male, $39.2 \%$ female and overall mean age of 15 years). We inquired about participants self-reported injuries in the past one year (all injury inclusive). When reported, injuries were further assessed according to cause, intent, nature, type, place, and number of days absent from school due to injury. Overall, there were 549 self-reported injuries

\footnotetext{
*Competing Interests: The authors have no competing interests to declare.

Authors' Contributions: JCN was the principal investigator and was responsible for study design, data acquisition, analysis and interpretation, and drafting of the manuscript. KHN was involved in data collection. KG, JT and FD participated in the study design and reviewing of the manuscript for intellectual content. All authors read and approved the final manuscript.
}

in the past one year (93.8\%) among the respondents $\mathbf{1 9 5 . 5 \%}$ for males and $\mathbf{9 0 . 8 \%}$ for females, $p$ $=0.6696$ ). Sex wise, prevalence of injury differ by age, school setting and parents' occupation $(p<0.05)$. Falls $293(53.4 \%)$ was the leading cause of injury. Falls and animal bites were significantly higher in males compared to females [206 (60.4\%) vs $87(41.8 \%) p=0.002$, and 10 $(2.9 \%)$ vs $0(0.0) p=0.016]$ respectively. Traffic injuries and falls decrease progressively with age. Homes and schools were settings injuries occurred mostly. Over $68 \%$ of the reported injuries were unintentional. On the average, 2 days of normal school activity were lost per injured persons because of an injury. Given the high prevalence of injury reported in this study, injury like tropical diseases, should be considered a significant public health problem in Nigeria. We expect that this school-based information will be useful in establishing rational priorities for prevention, and the targeting of interventions toward responsible authorities. Also, there is a high need for safety education aiming to educate this young population on how to prevent injury.

Keywords: School-Based; Self-Reported; Injury; Prevalence; Students; Nigeria

\section{INTRODUCTION}

Injuries constitute a major public health problem globally that accounts for more than 5 million deaths annually $[1,2]$. Recent projections hold that deaths resulting from injuries will increase from 5 million to over 8 million in 2020 [3-5]. The majority of all injury-related deaths occur in low and middle-income countries [6-8] 
where information is scarce regarding injury distribution, pattern and prevention [9], as well as lack of resources for care following injury [7].

Several epidemiological studies have been conducted on injuries. Many of such studies had focused on the types of injuries and their socio-economic status factors $[10,11]$, intent of injuries [12], pattern of sport related injuries [13], perception of injuries [14,15] and risk behaviors and injuries $[16,17]$. Although, injury has imposed a huge public health burden, studies had reported that over $70 \%$ of injuries are preventable by simple and reasonable means $[12,18,19]$.

Injury causation is a multi-factorial phenomenon in which place of injury plays a very significant role [20]. Other than homes, schools have been found to be a common place of injuries. Furthermore, children and adolescent students spend a significant amount of their time at schools where many factors predispose them to different types of injuries. For example, the contact of the students amongst themselves during sports-related activities and with the environment can act as possible contributing factors towards injury. The majority of injuries that happen in school are however non-fatal in nature [20].

The magnitude, characteristics and pattern of injury vary considerably from country to country [5]. Yet, school-based injury as a research problem has been largely ignored in developing countries including Nigeria. Few studies have described the pattern of injuries, and associated factors, in Nigeria. However, the majority of these studies have been hospital-based which provide information on severe injuries [21].

Notably, many childhood and adolescent injuries do not result in hospital attendance and, in any case, admissions to hospital present only a partial picture of the circumstances in which injuries occur. Also, there is limited access to hospital care in poor countries. More importantly, there is evidence that school age children often report injuries of which parents are not aware, thus for these older children, parents may not be able to report the full extent of injuries $[22,23]$. Thus on the premises of these limitations, it is evident that school-based study may be considered a simple and better approach to understand more accurately the pattern of injuries among children and adolescent.

However, the descriptive epidemiology of injury among adolescent students in Nigeria is poorly understood, as a result accurate information on injury among schooling adolescents is lacking. Therefore, to develop effective injury prevention strategies for schools in Nigeria and similar low-income settings, this study examined the distribution of injury among schooling adolescents with respect to sex, age, intent, mechanism and types of injury among adolescents in Southern Nigeria.

\section{METHODS}

\subsection{Participants}

A total of 600 students from selected schools in Delta State Southern Nigeria, voluntarily participated in the study. Of the 600 students, incomplete data were removed and 585 were included in the analysis. Of these, $60.9 \%$ were male while $39.1 \%$ were female. The slight male predominance in the sample was because one of the schools is same sex (boys only) school. The average age of male participants was $15.0 \pm 2.0$ years while for female was $15.2 \pm 1.7$ years. The average age of all participants was $15.1 \pm 1.9$ years. The participants cut across both public and private schools and their parents were from varied educational and occupational backgrounds.

\subsection{Study Design, Data Collection and Survey Instrument}

The study design was a cross-sectional survey conducted at Delta State Southern Nigeria between July and August, 2013 using a self-administered questionnaire on general school health survey. The injury section was adapted from previous published study [7]. Socio-demographic and injury related information was collected with a structured questionnaire. The questionnaires were administered to students by trained field interviewers who explained how to fill out the instruments to the students. The questionnaire was completed anonymously. Prior to the study, participants were pre informed of the significance of the research and informed consent was obtained from those who agreed to participate in the study. Also, approval was obtained from the respective schools.

The questionnaire consisted of different sections. Demographic data; such as age, sex, setting of residence etc. (1), Injury (2), students were asked to report injury sustained during the past one year. Respondents who reported at least one injury were requested to answer a series of questions related to the place, mechanism, types and intent of injury respectively etc. Also assessed were; highest level of parents' education: This is based on students self-reports and is divided into four levels: 1) not educated (illiterate); 2) primary school; 3) secondary education; 4) tertiary education; and parents' occupation: A more direct measure of the family economic situation was derived from a question reporting the occupation of the parents. This is based on students self-reports and responses were 1) none; 2) farming; 3) fishing; 4) business/trading; 5) civil servant; 6) others. In the analysis, where necessary, "no response" or "do not know" were combined with others.

\subsection{Analysis}

Descriptive analyses of age, sex, mechanism, intent, 
types of injury and days of activity lost due to injury, were performed using STATISTICA version 12.0 and GraphPad Prism version 5.0. Chi-square test was used to compare differences among subjects by socio-demographic characteristics. Student $t$-test was used for parametric variables and where appropriate one-way ANOVA was also used to assess significant differences. All reported $P$ values were made on the basis of two-tailed tests. Differences were considered statistically significant at $P$ value $<0.05$.

\section{RESULTS}

\subsection{Characteristics of the Participants}

A total of 585 students participated in the study. Most of the participants were males $(60.9 \%)$, and (39.2\%) were females. The mean age of the study population was 15 years. More than half of the study population resided in the urban area (65.8\%). Overall, $45.0 \%$ attend public school while $55.0 \%$ attend private school. The majority of the students' parents had tertiary education $(66.0 \%)$, while less than $2 \%$ were uneducated, and $46.7 \%$ of the students' parents were into business/trading while less than $1 \%$ were unemployed (Table 1).

\subsection{Prevalence of Self-Reported Injuries among the Participants}

Overall, there were 549 self-reported injuries in past one year (93.8\%) among the respondents $(95.5 \%$ for males and $90.8 \%$ for females, $P=0.6696$ ). Sex wise, prevalence of injury differ by age, school setting, school ownership and parents' occupation $(P<0.05)$, but the difference in injuries with respect to parents' level of education was not significant $(P=0.6111)$ (Table 2).

\subsection{Cause of Injury}

Overall, falls 293 (53.4\%) was the leading cause of in-

Table 1. Characteristics of the participants.

\begin{tabular}{|c|c|c|c|c|}
\hline Variables & Total $(\mathrm{N}=585)$ & Male $(\mathrm{N}=356)$ & Female $(\mathrm{N}=229)$ & $P$ value \\
\hline \multicolumn{5}{|l|}{ Age (years) } \\
\hline$\leq 13$ & $134(22.9)$ & $97(27.2)$ & $37(16.2)$ & 0.0030 \\
\hline $14-17$ & $410(70.1)$ & $235(66.0)$ & $175(76.4)$ & 0.5410 \\
\hline$\geq 18$ & $41(7.0)$ & $24(6.7)$ & $17(7.4)$ & 0.3874 \\
\hline \multicolumn{5}{|l|}{ School setting } \\
\hline Rural & $200(34.2)$ & $191(53.7)$ & $9(3.9)$ & 0.0001 \\
\hline Urban & $385(65.8)$ & $165(46.4)$ & $220(96.1)$ & \\
\hline \multicolumn{5}{|l|}{ School ownership } \\
\hline Public & $263(45.0)$ & $210(59.0)$ & $53(23.1)$ & 0.0001 \\
\hline Private & $322(55.0)$ & $146(41.0)$ & $176(76.9)$ & \\
\hline \multicolumn{5}{|c|}{ Parent's level of education } \\
\hline Illiterate & $11(1.9)$ & $6(1.7)$ & $4(1.8)$ & 0.6710 \\
\hline Primary & $30(5.1)$ & $18(5.1)$ & $12(5.2)$ & \\
\hline Secondary & $133(22.7)$ & $74(20.8)$ & $59(25.8)$ & \\
\hline Tertiary & $386(66.0)$ & $243(68.3)$ & $143(62.5)$ & \\
\hline No response & $26(4.4)$ & $15(4.2)$ & $11(4.8)$ & \\
\hline \multicolumn{5}{|l|}{ Parent's occupation } \\
\hline Unemployed & $4(0.7)$ & $2(0.6)$ & $2(0.9)$ & 0.0095 \\
\hline Farmer & $26(4.4)$ & $20(5.6)$ & $6(2.6)$ & \\
\hline Fishing & $6(1.0)$ & $2(0.6)$ & $4(1.8)$ & \\
\hline Business/trader & $273(46.7)$ & $150(42.1)$ & $123(53.7)$ & \\
\hline Civil servant & $188(32.1)$ & $130(36.5)$ & $58(25.3)$ & \\
\hline Others & $88(15.0)$ & $52(14.6)$ & $36(15.7)$ & \\
\hline
\end{tabular}


Table 2. Prevalence of self-reported injuries among the participants with respect to sex $(\mathrm{N}=585)$.

\begin{tabular}{|c|c|c|c|c|c|}
\hline \multirow{2}{*}{ Variables } & \multicolumn{2}{|c|}{ Male $(\mathrm{N}=356)$} & \multicolumn{2}{|c|}{ Female $(\mathrm{N}=229)$} & \multirow{2}{*}{$P$ value } \\
\hline & Total & Number injured & Total & Number injured & \\
\hline Total prevalence & $356(100.0)$ & $341(95.8)$ & $229(100.0)$ & $208(90.8)$ & 0.6696 \\
\hline \multicolumn{6}{|l|}{ Age (years) } \\
\hline$\leq 13$ & $97(27.2)$ & $96(99.0)$ & $37(16.2)$ & $30(81.1)$ & \multirow[t]{3}{*}{0.0009} \\
\hline $14-17$ & $235(66.0)$ & $221(94.4)$ & $175(76.4)$ & $163(93.0)$ & \\
\hline$\geq 18$ & $24(6.7)$ & $24(100.0)$ & $17(7.4)$ & $15(88.0)$ & \\
\hline \multicolumn{6}{|l|}{ School setting } \\
\hline Rural & $191(53.65)$ & $190(99.5)$ & $9(3.93)$ & $9(100.0)$ & \multirow[t]{2}{*}{0.0001} \\
\hline Urban & $165(46.35)$ & $151(91.5)$ & $220(96.07)$ & $199(90.0)$ & \\
\hline \multicolumn{6}{|l|}{ School ownership } \\
\hline Public & $210(58.99)$ & $205(97.6)$ & $53(23.14)$ & $47(89.0)$ & \multirow[t]{2}{*}{0.0001} \\
\hline Private & $146(41.01)$ & $136(93.0)$ & $176(76.86)$ & $161(91.0)$ & \\
\hline \multicolumn{6}{|l|}{ Parent's level of edu* } \\
\hline Illiterate & $6(1.69)$ & $4(67.0)$ & $4(1.75)$ & $3(75.0)$ & \multirow[t]{5}{*}{0.6111} \\
\hline Primary & $18(5.06)$ & $17(94.4)$ & $12(5.24)$ & $10(83.0)$ & \\
\hline Secondary & $74(20.79)$ & $72(97.3)$ & $59(25.76)$ & $54(92.0)$ & \\
\hline Tertiary & $243(68.26)$ & $236(97.2)$ & $143(62.45)$ & $131(92.0)$ & \\
\hline No response & $15(4.21)$ & $12(80.0)$ & $11(4.80)$ & $10(91.0)$ & \\
\hline \multicolumn{6}{|l|}{ Parent's occupation } \\
\hline Unemployed & $2(0.56)$ & $2(100.0)$ & $2(0.87)$ & $2(100.0)$ & \multirow[t]{6}{*}{0.0106} \\
\hline Farmer & $20(5.62)$ & $16(80.0)$ & $6(2.62)$ & $6(100.0)$ & \\
\hline Fishing & $2(0.56)$ & $2(100.0)$ & $4(1.75)$ & $4(100.0)$ & \\
\hline Business/trader & $150(42.13)$ & $145(97.7)$ & $123(53.71)$ & $114(93.0)$ & \\
\hline Civil servant & $130(36.52)$ & $126(96.9)$ & $58(25.33)$ & $49(84.0)$ & \\
\hline Others & $52(14.61)$ & $50(96.0)$ & $36(15.72)$ & $33(92.0)$ & \\
\hline
\end{tabular}

${ }^{*}$ edu = education.

jury among the study population; followed by cuts/ stabs $52(9.5 \%)$, and fire/heats 41 (7.5\%). Sex wise, falls and animal bites were significantly higher in males compared to females [206 (60.4\%) vs $87(41.8 \%) P=$ 0.002 , and $10(2.9 \%)$ vs $0(0.0) P=0.016$ ] respectively, while sexual assault and other were significantly higher in females than in males [9 $(4.3 \%)$ vs $2(0.6 \%) P=0.004$, and $47(22.6 \%)$ vs $34(10.0 \%) P=0.001]$ respectively. In all cause of injuries, there was significant difference in the prevalence among female $(P=0.042)$, (Table 3). As expected, the cause of injury varied with age group (Table 4). Traffic injuries and falls decreases progressively with age while sexual assault, fire/heat, and stabs/cut increases with age. Injuries caused by animal bites were more common among aged $\leq 13$ and $\geq 18$ years. Although, there was no significant different in the cause of injury across age groups, in all cause of injuries, there was significant difference for aged $\geq 18$ years $(P=0.012)$, (Table 4).

\subsection{Intent of Injury}

Overall, about $68.7 \%$ of the reported injuries were unintentional in nature, $13.3 \%$ were unintentional (self-inflicted) and $3.5 \%$ were intentional. Sex-wise, there was significant difference of the intent of injury $(P=0.001)$. Of the 341 injuries among males, $78.9 \%$ were unintentional while among female $46.2 \%$ of the 208 injuries 
Table 3. Cause of injury in relation to sex.

\begin{tabular}{|c|c|c|c|c|}
\hline Cause of injury & Overall & Male & Female & $P$ value \\
\hline Traffic injury & $32(5.8)$ & $23(6.7)$ & $9(4.3)$ & 0.3477 \\
\hline Fall & $293(53.4)$ & $206(60.4)$ & $87(41.8)$ & 0.0188 \\
\hline Sexual assault & $11(2.0)$ & $2(0.6)$ & $9(4.3)$ & 0.0043 \\
\hline Fire/heat & $41(7.5)$ & $21(6.2)$ & $20(9.6)$ & 0.1850 \\
\hline $\mathrm{Stab} /$ cut & $52(9.5)$ & $26(7.6)$ & $26(12.5)$ & 0.1016 \\
\hline Blunt injury & $15(2.7)$ & $12(3.5)$ & $3(1.4)$ & 0.1862 \\
\hline Gunshot & $1(0.2)$ & $0(0.0)$ & $1(0.5)$ & 0.3800 \\
\hline Drowning & $2(0.4)$ & $0(0.0)$ & $2(1.0)$ & 0.1448 \\
\hline Chocking/hanging & $2(0.4)$ & $0(0.0)$ & $2(1.0)$ & 0.1448 \\
\hline Poisoning & $2(0.4)$ & $2(0.6)$ & $0(0.0)$ & 0.5292 \\
\hline Animal bite & $10(1.8)$ & $10(2.9)$ & $0(0.0)$ & 0.0161 \\
\hline Electric shock & $7(1.3)$ & $5(1.5)$ & $2(1.0)$ & 0.7154 \\
\hline Other & $81(14.8)$ & $34(10.0)$ & $47(22.6)$ & 0.0007 \\
\hline Total & $549(100.0)$ & $341(100.0)$ & $208(100.0)$ & \\
\hline
\end{tabular}

Table 4. Cause of injury in relation to age.

\begin{tabular}{|c|c|c|c|c|c|}
\hline Cause of injury & Total & $\leq 13$ & $14-17$ & $\geq 18$ & $P$ value \\
\hline Traffic injury & $32(5.8)$ & $10(7.9)$ & $21(5.5)$ & $1(2.6)$ & 0.5508 \\
\hline Fall & $293(53.4)$ & $83(65.9)$ & $197(51.3)$ & $13(33.3)$ & 0.0912 \\
\hline Sexual assault & $11(2.0)$ & $0(0.0)$ & $7(1.8)$ & $4(10.3)$ & 0.5941 \\
\hline Fire/heat & $41(7.5)$ & $8(6.4)$ & $26(6.8)$ & $7(17.9)$ & 0.5421 \\
\hline $\mathrm{Stab} / \mathrm{cut}$ & $52(9.5)$ & $7(5.6)$ & $38(9.9)$ & $7(17.9)$ & 0.5062 \\
\hline Blunt injury & $15(2.7)$ & $1(0.8)$ & $14(3.6)$ & $0(0.0)$ & 0.5700 \\
\hline Gunshot & $1(0.2)$ & $0(0.0)$ & $1(0.3)$ & $0(0.0)$ & 0.6070 \\
\hline Drowning & $2(0.4)$ & $0(0.0)$ & $1(0.3)$ & $1(2.6)$ & 0.6081 \\
\hline Chocking/hanging & $2(0.4)$ & $0(0.0)$ & $2(0.5)$ & $0(0.0)$ & 0.6042 \\
\hline Poisoning & $2(0.4)$ & $0(0.0)$ & $2(0.5)$ & $0(0.0)$ & 0.6042 \\
\hline Animal bite & $10(1.8)$ & $3(2.4)$ & $6(1.6)$ & $1(2.6)$ & 0.5941 \\
\hline Electric shock & $7(1.3)$ & $0(0.0)$ & $6(1.6)$ & $1(2.6)$ & 0.5939 \\
\hline Other & $81(14.8)$ & $14(11.1)$ & $63(16.4)$ & $4(10.3)$ & 0.4277 \\
\hline Total & $549(100.0)$ & $126(100.0)$ & $384(100.0)$ & $39(100.0)$ & \\
\hline
\end{tabular}

were unintentional. The rate of unintentional (self-inflicted) and intentional injuries were higher among females compared to males (Figure 1).

\subsection{Place of Injury}

Generally, homes, schools and during sports were where injuries occurred mostly. There was significant sex difference in injury setting $(P=0.001)$, (Figure 2). For males, home injuries has the highest ratio (48.7\%) followed by school (19.9\%), and sport (15.0\%), similarly, for females, home injuries has the highest ratio $(46.2 \%)$ followed by others (20.7\%), and school (13.9\%), (Figure 2). 


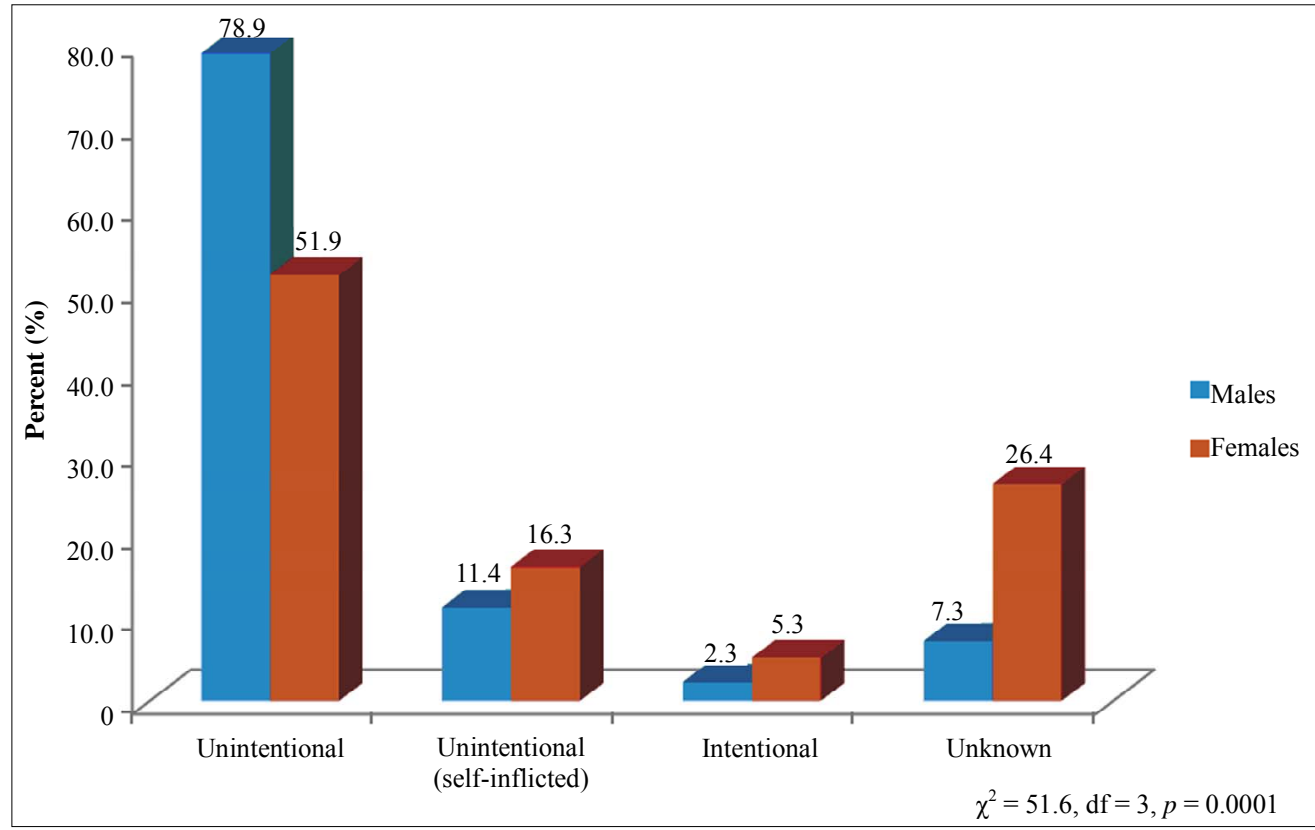

Figure 1. Intent of injury.

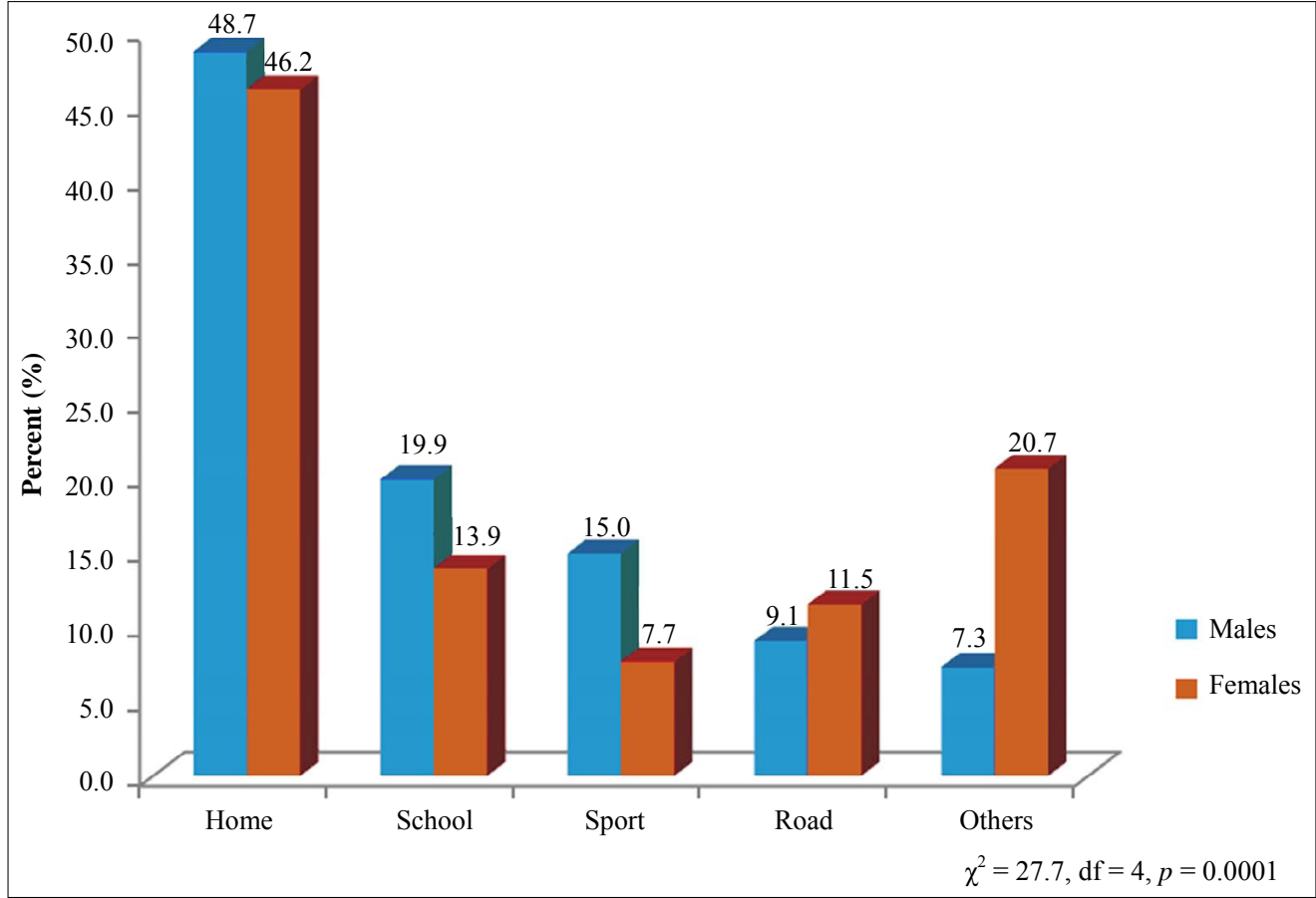

Figure 2. Place of injury.

\subsection{Types of Injury}

Table 5 presents the distribution of types of injury in relation to sex and age. The commonly reported injuries were bruises and cuts/bite/open wounds followed by other unclassified injuries and sprains; least common were internal injuries and concussion. For all types of injures, there was significant sex difference within age groups $(P<0.05)$. Across age groups, the prevalence of fracture, bruise and sprain/strain was higher among males than females. Though significant sex difference was only observed among age group $14-17$ years for bruise $(P<0.05)$. On the other hand, the prevalence of cut/bite/open wounds and unclassified injuries was higher among females than males (Table 5). 
Table 5. Percentage distribution of injury types in relation to sex and age.

\begin{tabular}{|c|c|c|c|c|c|c|}
\hline \multirow{3}{*}{ Injury types } & \multicolumn{2}{|c|}{$\leq 13^{* *}$} & \multicolumn{2}{|c|}{$14-17^{* *}$} & \multicolumn{2}{|c|}{$\geq 18^{* *}$} \\
\hline & Male & Female & Male & Female & Male & Female \\
\hline & $N=96$ & $\mathrm{~N}=30$ & $\mathrm{~N}=221$ & $\mathrm{~N}=163$ & $\mathrm{~N}=24$ & $\mathrm{~N}=15$ \\
\hline Fracture & $17(17.7)$ & $3(10.0)$ & $29(13.1)$ & $18(11.0)$ & $4(16.7)$ & $1(6.7)$ \\
\hline Bruise & $26(27.1)$ & $3(10.0)$ & $49(22.2)$ & $20(12.3)^{*}$ & $6(25.0)$ & $1(6.7)$ \\
\hline Sprain/strain & $6(6.3)$ & $2(6.7)$ & $12(5.4)$ & $3(1.8)$ & $1(4.2)$ & $0(0.0)$ \\
\hline Burn & $11(11.5)$ & $3(10.0)$ & $14(6.3)$ & $13(8.0)$ & $1(4.2)$ & $4(26.7)$ \\
\hline Cut/bite/open/wound & $25(26.0)$ & $9(30.0)$ & $66(29.9)$ & $59(36.2)$ & $8(33.3)$ & $2(13.3)$ \\
\hline Concussion & $0(0.0)$ & $0(0.0)$ & $2(0.9)$ & $1(0.6)$ & $0(0.0)$ & $0(0.0)$ \\
\hline Internal injury & $1(1.0)$ & $0(0.0)$ & $9(4.1)$ & $4(2.5)$ & $1(4.2)$ & $0(0.0)$ \\
\hline Others & $10(10.4)$ & $10(33.3)^{*}$ & $40(18.1)$ & $45(27.6)$ & $3(12.5)$ & $7(46.7)$ \\
\hline
\end{tabular}

${ }^{*} \mathrm{P}<0.05$; Significance values are for sex comparison for injury type. ${ }^{* *} \mathrm{P}<0.05$; Significance values are for sex comparison for age group.

\subsection{Initial Help Sought during Injury}

Figure 3 presents information on initial help sought by the injured persons. There was significant variation on the category of persons from which help was sought $(P=$ 0.0039 ). About $68.1 \%$ and $62.0 \%$ of the injured males and females respectively reported been helped by friend/ family at time of injury. For both males and female, only less than $8.0 \%$ were initially assisted by teacher.

\subsection{Absence from School Due to Injury}

As seen from Figure 4, absenteeism from school due to injury was not common among the study population. For example, $69.5 \%$ and $74.5 \%$ of the injured males and females respectively reported not been absent from school due to injury sustained. However, about 20.7\% and $23.5 \%$ of males and females respectively reported been absent from school for less than one week due to injury, while only about $1.0 \%$ of both males and females reported been absent from school for over 4 weeks. There was no sex differences in school absenteeism due to injury ( $P=0.575$ ). On the average, 2 days of normal school activity were lost per injured persons because of an injury.

\section{DISCUSSION}

Globally, injuries are gaining recognition as an emerging public health problem that affects all age population, especially adolescents. With the growing awareness of injuries as a preventable events, information on injuries among young students, would aid policy makers and school managements alike in the planning of prevention and intervention strategies.

To the best of our knowledge, this is the first report on the prevalence and pattern of injuries among students in

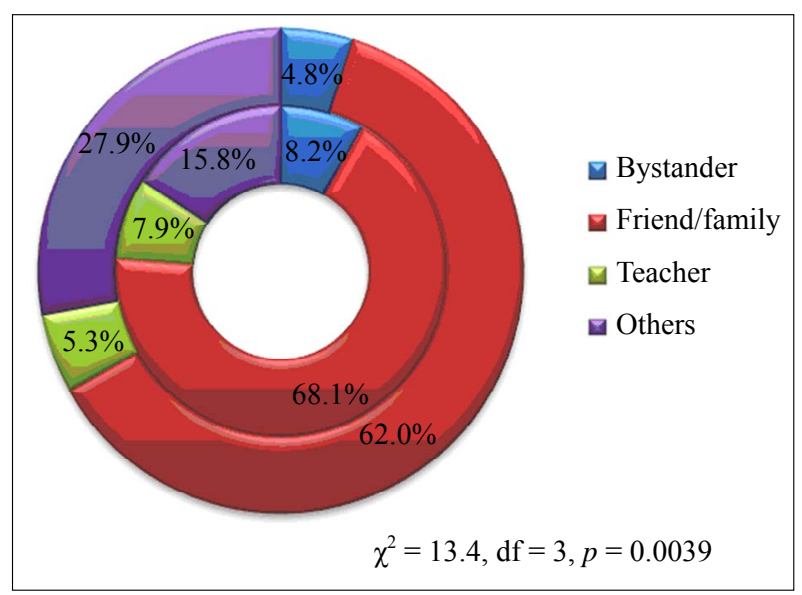

Figure 3. Help seeking pattern of the injured (inner doughnut is for males, outter for females).

Delta State Southern Nigeria. This study revealed a high prevalence $(93.8 \%)$ of injury among the student population. This figure is quite higher than the reports from some African countries [24-26]. The high prevalence could be explained by the broader definition used for injury to include all injuries regardless of severity, as against other studies that considered only injuries that led to treatment in the hospital or time loss. However, similar high prevalence of injury has been reported in China $(81.7 \%)$ [27]. Furthermore, the rate of injuries was higher among males than females. Considerable numbers of studies around the globe has reported similar findings $[7,8,10,12,28]$. This is probably because males have higher levels of sensation seeking [29-31], and are more impulsive [32] thus are more likely to engage in risky behaviour than females [32-34].

Regarding the cause of injury, fall ranked highest as the leading cause of injury among the study participants; 


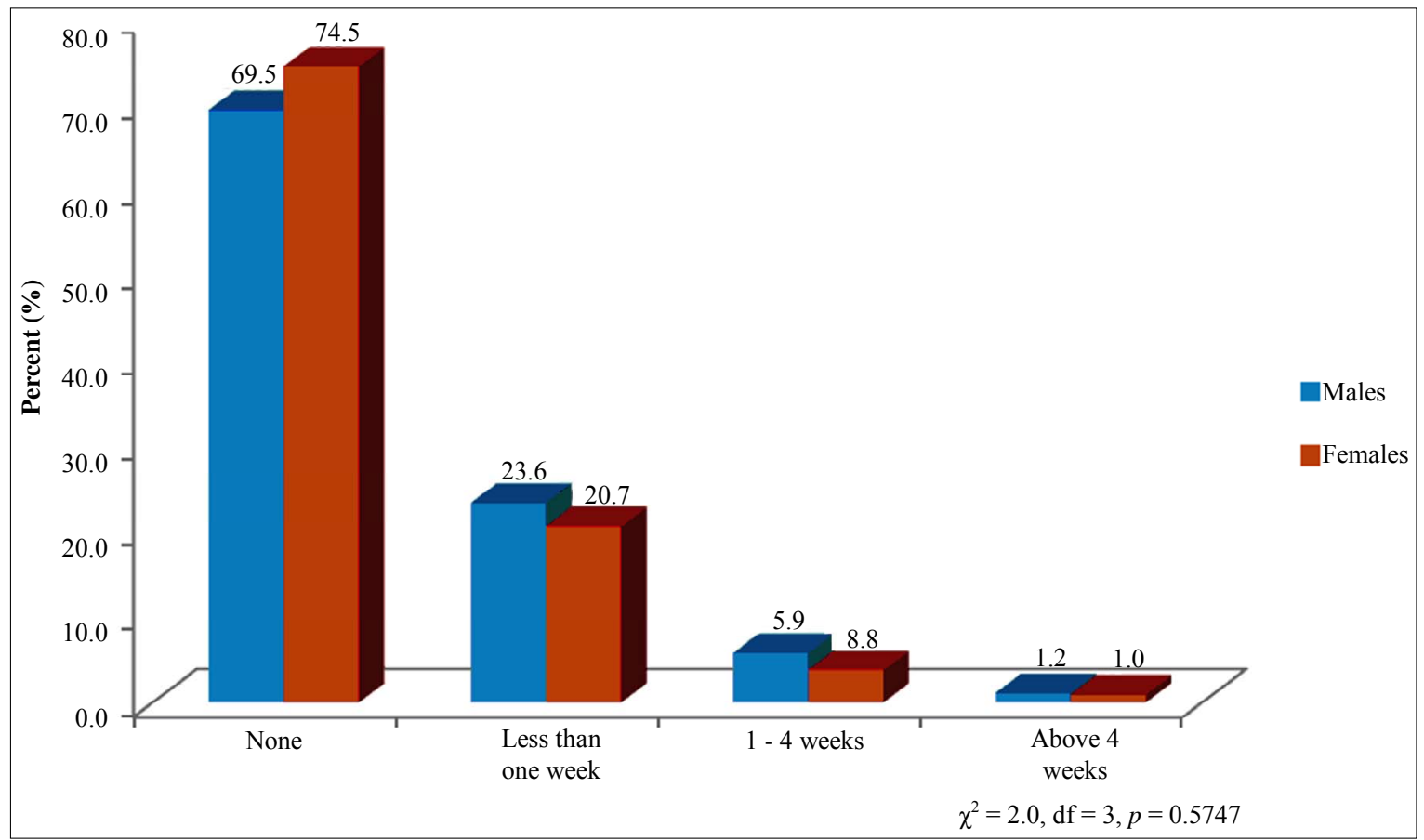

Figure 4. Period of absence from school due to injury.

followed by cuts/stabs. As expected, the rate of fall was significantly higher in males than females. This study conforms to other reports that have identified falls as the predominant cause of injury among adolescents $[12,28$, $33,35,36]$. The prevention of falls is undetermined by the numerous factors leading up to them, thus this is a challenge for both school and community based education program. Child falls may occur largely as a result of their innate curiosity of their surroundings, risk taking characteristics $[33,37]$ and immature judgment.

Adolescent falls may be associated with their personality like high-level activity. Thus adolescent falls during activities in school must not be overlooked. Additionally, the impact of fall injuries among students may be great depending on severity of fall. Falls may result in sprains, dislocations, bruises, lacerations and cuts, and can even lead to disability and time off from school [33]. Animal bites were another cause of injury that was significantly higher among males. The probable reason for this is unclear, however, it is reasonable to infer that since males are more adventurous and experimenting in nature, these habits may have exposed them to frequent animal bites. Furthermore, burns/heat and cuts were more frequent among females. This could be explained by the higher propensity of females to engage in cooking as the African custom considers cooking and kitchen activities the primary birth responsibility of female.

Age is an important risk factor for many injuries but its influence varies between specific injury groups. Here, our study shows that the cause of injury varied with age group. For example, traffic injuries and falls decreases progressively with age while sexual assault, fire/heat, and stabs/cut increases with age. Injuries caused by animal bites were more common among aged $\leq 13$ and $\geq 18$ years. The decrease of traffic and falls related injuries may be explained by increased level of safety consciousness with increase in age. Also, our finding shows that for all types of injuries, there was significant sex difference within age groups $(P<0.05)$ this observation is consistent with findings from other study [4,7]. Report on the intent of injuries revealed that about $70 \%$ of the reported injuries were unintentional. Also, female students were more likely to report unintentional (self-inflicted) injuries.

These findings agrees with the reports of Black et al. [38] that unintentional injuries were most common for both male (67\%) and female (75\%) youth across all age groups. This suggests that many actions leading to injury occur in moments of distraction or high emotion and the intent to injure may be peripheral to the action.

The occurrence of most injuries in the home followed by the school is in consonance with the findings of Jildeh et al. [12] among others. This underscores the importance of home and school environment in the causation of injuries. That majority of the injured persons initially sought help or were attended to by friends/family, and bystanders members further implicate home and it's environ but not school as the principal place of injury among this population. Although we did not assess the severity of the reported injuries, it reasonable to infer 
from the low rate of school absenteeism that majority of the injuries were not severe.

\subsection{Limitation and Strength}

Like any other study in the world, our study had a number of drawbacks. First, data were collected through a self-reported structured questionnaire. Thus responses to the occurrence and nature of injury could not be verified. Given that it is not impossible that some of the study participants may have under-reported or mis-reported intentionally, especially for injuries associated with domestic or sexual violence respectively. An accurate evidence-based data should minimize this however such data are difficult to come by especially in developing nations. Second, the possibility of recall bias cannot be rule out. Considering the likelihood that detail of the injury could be lost due to memory-decay, and/or "telescoping" resulting in the inclusion of injury events that occurred outside the recall period. We proposed that a short recall period of 6 months should minimize this. Third, we did not consider multiple injuries, severity of injury and the use of all inclusive definition of injury may have blown up the prevalence. Although we considered that an all-inclusive definition of injury may give a better picture of the injury pattern among this population, further studies are needed to understand the severity of specific injuries among this population. Given the above mentioned limitations, we suggest that generalizing our findings to other setting should be treated with caution. Despite these limitations, this is the first study to investigate prevalence and pattern of injuries among student in Southern Nigeria. It looked at a large population of students and is considered to be the baseline for future studies. Our ability to focus exclusively on students would be helpful for designing injury prevention programs for student population in similar settings.

\subsection{Conclusions}

This study is the first to report the prevalence and pattern of injury among students in Delta State Southern Nigeria. With an overall prevalence of about $93.8 \%$, injury should be a major public health concern in Southern Nigeria. It has attempted to identify the ranges of injuries common among this population and the age-sex patterns. We envisage that this information will be relevant in raising the level of awareness among policy makers and the public in general since the problem of injury receives little attention in most of the developing world including Nigeria. Our finding that falls and homes are the leading cause and place of injury respectively will also be useful in setting priorities for cause specific prevention strategies focusing on adolescents' injury prevention. To develop comprehensive and multifaceted evidence-based prevention strategies, there is an urgent need for additional studies to investigate the risk factors associated with injury prevalence, cause and outcomes.

Finally, a major limitation to the development of efficacious injury prevention strategies in many developing countries is the lack of acknowledgement of their importance by the public and many policy makers. Therefore, findings reported in this study need to be brought to light on a wider scale. There is sufficient evidence of the significance of injury as a public health problem that increased attention should be paid to it by national governments and other public health organizations [39,40].

\section{ACKNOWLEDGEMENTS}

The authors wish to acknowledge the cooperation of the students who participated in the study. This research was supported by fund for scientific research from the Osaka Kyoiku University. The funders had no role in study design, data collection and analysis, decision to publish, or preparation of the manuscript.

\section{REFERENCES}

[1] World Health Organization (2008) Violence, injuries, and disability: Biennial 2006-2007 report. World Health Organization, Geneva.

[2] Sethi, D., Habibula, S., McGee, K., Peden, M., Bennett, S., Hyder, A.A., Klevens, J., Odero, W. and Suriyawongpaisal, P. (2004) Guidelines for conducting community surveys on injuries and violence. World Health Organization.

[3] Murray, C.J. and Lopez, A.D. (1997) Alternative projections of mortality and disability by cause 1990-2020: Global burden of disease study. Lancet, 349, 1498-1504. http://dx.doi.org/10.1016/S0140-6736(96)07492-2

[4] Maziak, W., Ward, K.D. and Rastam, S. (2006) Injuries in Aleppo, Syria; first population-based estimates and characterization of predominant types. BMC Public Health, 6, 63. http://dx.doi.org/10.1186/1471-2458-6-63

[5] Fatmi, Z., Hadden, W.C., Razzak, J.A., Qureshi, H.I., Hyder, A.A. and Pappas, G. (2007) Incidence, patterns and severity of reported unintentional injuries in Pakistan for persons five years and older: Results of the National Health Survey of Pakistan 1990-94. BMC Public Health, 7, 152. http://dx.doi.org/10.1186/1471-2458-7-152

[6] Hafman, K., Primack, A., Keusch, G. and Hrynkow, S. (2005) Global health concerns: Addressing the growing burden of trauma and injury in low and middle-income countries. American Journal of Public Health, 95, 13-17. http://dx.doi.org/10.2105/AJPH.2004.039354

[7] Olawale, O.A. and Owoaje, E.T. (2007) Incidence and pattern of injuries among residents of a rural area in South-Western Nigeria: A community-based study. BMC Public Health, 7, 246. http://dx.doi.org/10.1186/1471-2458-7-246

[8] Ghaffar, A., Hyder, A.A. and Masud, T.I. (2004) The burden of road traffic injuries in developing countries: The 
first national survey of Pakistan. Public Health, 118, 211217. http://dx.doi.org/10.1016/j.puhe.2003.05.003

[9] Hang, H.M., Ekman, R., Bach, T.T., Byass, P. and Svanström, L. (2003) Community-based assessment of unintentional injuries: A pilot study in rural Vietnam. Scandinavian Journal of Public Health, 62, 38-44. http://dx.doi.org/10.1080/14034950310015095

[10] Pickett, W., Michal, M.K., Simpson, I.J., Emmanuel, K.J., Mazur, Y.H. and William, F.B. (2005) Cross national study of injury and social determinants in adolescents. Injury Prevention, 11, 213-218. http://dx.doi.org/10.1136/ip.2004.007021

[11] Marcenes, W. and Zabot, T. (2001) Socio-economic correlates of traumatic injuries to the permanent incisors in schoolchildren aged 12 years in Blumenau, Brazilian. Dental Traumatology, 17, 218-222. http://dx.doi.org/10.1034/j.1600-9657.2001.170507.x

[12] Jildeh, C., Abdeen, Z., Sabbah, H.A. and Philalithis, A. (2013) Unintentional injuries among school-aged children in Palestine: Findings from the national study of palestinian schoolchildren (HBSC-WBG2006). International Journal of Population Research, 2013.

[13] Owoeye, O.B., Akodu, A.K., Oladokun, B.M. and Akinbo, S.R. (2012) Incidence and pattern of injuries among adolescent basketball players in Nigeria. Sports Medicine, Arthroscopy, Rehabilitation, Therapy and Technology, 4, 15.

[14] Butchart, A., Kruger, J. and Lekoba, R. (2000) Perceptions of injury causes and solutions in a Johannesburg township: Implications for prevention. Social Science and Medicine, 50, 331-344. http://dx.doi.org/10.1016/S0277-9536(99)00272-5

[15] Ibrahim, J.M., Day, H., Hirshon, JM. and El-Setouhy, M. (2012) Road risk-perception and pedestrian injuries among students at Ain Shams University, Cairo, Egypt. Journal of Injury and Violence Research, 4, 65-72. http://dx.doi.org/10.5249/jivr.v4i2.112

[16] Pickett, W., Garner, M.J., Boyce, W.F. and King, M.A. (2002) Gradients in risk for youth injury associated with multiple-risk behaviours: A study of 11,329 Canadian adolescents. Social Science and Medicine, 55, 1055-1068. http://dx.doi.org/10.1016/S0277-9536(01)00224-6

[17] Pickett, W., Schmid, H., Boyce, W.F., Simpson, K., Scheidt, P.C., Mazur, J., Molcho, M., King, M.A., Godeau, E., Overpeck, M., Aszmann, A., Szabo, M. and Harel, Y. (2002) Multiple risk behavior and injury: An international analysis of young people. Archives of Pediatrics and Adolescent Medicine, 156, 786-793. http://dx.doi.org/10.1001/archpedi.156.8.786

[18] Bergman, A.B. and Rivara, F.P. (1991) Sweden's experience in reducing childhood injuries. Pediatrics, 88, 6974.

[19] Onwuachi-Saunders, C., Samuel, N.F., Patricia, W. and Cimon, B. (1999) Child death reviews: A gold mine for injury prevention and control. Injury Prevention, 5, 276279. http://dx.doi.org/10.1136/ip.5.4.276

[20] Khan, U.R., Bhatti, J.A., Zia, N. and Farooq, U. (2013) School-based injury outcomes in children from a lowincome setting: Results from the pilot injury surveillance in Rawalpindi city, Pakistan. BMC Research Notes, 6, 86. http://dx.doi.org/10.1186/1756-0500-6-86

[21] Udoh, D.O. and Adeyemo, A.A. (2013) Traumatic brain injuries in children: A hospital-based study in Nigeria. African Journal of Paediatrics and Surgery, 10, 154-159. http://dx.doi.org/10.4103/0189-6725.115043

[22] Currie, C.E., Williams, J.M., Wright, P., Beattie, T. and Harel, Y. (1996) Incidence and distribution of injury among schoolchildren aged 11-15. Injury Prevention, 2, 21-25. http://dx.doi.org/10.1136/ip.2.1.21

[23] Towner, E.M.L., Jarvis, S.N., Walsh, S.S.M. and AynsleyGreen, A. (1994) Measuring exposure to injury risk in schoolchildren aged 11-14. Bio Medical Journal, 308, 449-452. http://dx.doi.org/10.1136/bmj.308.6926.449

[24] Peltzer, K. (2006) Injury and lifestyle factors among school-aged black and white South African children in the Limpopo Province. Journal of Injury Violence and Prevention, 4, 15-25.

[25] Starkuniviene, S. and Zaborski, A. (2005) Links between accidents and lifestyle factors among Lithuanian schoolchildren. Medicina, 41, 73-80.

[26] Peltzer, K. (2008) Injury and social determinants among in-school adolescents in six African countries. Injury Prevention, 14, 381-388. http://dx.doi.org/10.1136/ip.2008.018598

[27] Li, X.-S., Xuan, Y.-Q. and Zhu, M. (1997) An investigation on the epidemiology of injuries in middle school students. Chinese Journal of Epidemiology, 18, 146-149.

[28] Moshiro, C., Ivar, H., Anne, N.A., Philip, S., Yusuf, H. and Gunnar, K. (2005) Injury morbidity in an urban and a rural area in Tanzania: An epidemiological survey. BMC Public Health, 5, 11. http://dx.doi.org/10.1186/1471-2458-5-11

[29] Hampson, S.E., Andrews, J.A. and Barckley, M. (2008) Childhood predictors of adolescent marijuana use: Early sensation-seeking, deviant peer affiliation, and social images. Addiction and Behavior, 33, 1140-1147. http://dx.doi.org/10.1016/j.addbeh.2008.04.010

[30] Balan, B. and Lingam, L. (2012) Unintentional injuries among children in resource poor settings: Where do the fingers point? Archives of Disease in Childhood, 97, 3538. http://dx.doi.org/10.1136/archdischild-2011-300589

[31] Ball, I.L., Farnill, D. and Wangeman, J.F. (1984) Sex and age differences in sensation seeking: Some national comparisons. British Journal of Psycholology, 75, 257-265. http://dx.doi.org/10.1111/j.2044-8295.1984.tb01897.x

[32] Zuckerman, M., Eysenck, S.B. and Eysenck, H.J. (1978) Sensation seeking in England and America: Cross-cultural, age, and sex comparisons. Journal of Consulting and Clinical Psychology, 46, 139. http://dx.doi.org/10.1037/0022-006X.46.1.139

[33] Zhou, L., Chen, D. and Dong, G. (2013) Characteristics and related factors of nonfatal injuries among adolescents and college students in Shenzhen city of China. BMC Public Health, 13, 392. http://dx.doi.org/10.1186/1471-2458-13-392

[34] Boles, R.E., Roberts, M.C., Brown, K.J. and Mayes, S. (2005) Children's risk taking behaviors: The role of child- 
based perceptions of vulnerability and temperament. Journal of Pediatrics and Psychology, 30, 562-570.

[35] Janson, S., Aleco, M., Beetar, A., Bodin, A. and Shami, S. (1994) Accident risks for suburban preschool Jordanian children. Journal of Tropical Paediatrics, 40, 88-93. http://dx.doi.org/10.1093/tropej/40.2.88

[36] Broides, A. and Assaf, M. (2003) Home accidents in Arab Bedouin children in southern Israel. Journal of Child Health Care, 7, 207-214. http://dx.doi.org/10.1177/13674935030073006

[37] World Health Organization (2013) Falls. http:/www.who.int/mediacentre/factsheets/fs344/en/
[38] Black, K., Asbridge, M. and Lea, S. (2009) An overview of injuries to adolescents and young adults related to substance use: Data from Canadian emergency departments. Canadian Journal of Emergency Medicine, 11, 330-336.

[39] Mock, C.N., Abantanga, F., Cummings, P. and Koepsell, T.D. (1999) Incidence and outcome of injury in Ghana: A community-based survey. Bulletin of World Health Organization, 77, 955.

[40] Forjuoh, S.N., Zwi, A.B. and Mock, C.N. (1998) Injury control in Africa: Getting governments to do more. Tropical Medicine and International Health, 3, 349-356. http://dx.doi.org/10.1046/j.1365-3156.1998.00240.x 